\title{
North Korea suspends nuclear testing
}

United States offers food aid in exchange for moratorium on uranium enrichment and weapons testing.

\section{Geoff Brumfiel}

29 February 2012

The US Department of State today announced a breakthrough in negotiations with North Korea over the country's controversial nuclear programme.

Under the terms of the deal, North Korea will suspend nuclear testing, uranium enrichment and long-range ballistic-missile development in exchange for 240,000 tonnes of food aid from the United States. The agreement would also allow the International Atomic Energy Agency (IAEA) inspectors to enter the Yongbyon nuclear complex for the first time since 2009.

Of particular interest to the IAEA will be North Korea's uranium-enrichment programme at Yongbyon. Sig Hecker, a metallurgist at Stanford University in California, saw 2,000 centrifuges during an informal visit he made to the site in 2010, but international inspectors have never officially had access to the facility.

This isn't the first time that North Korea has used its nuclear programme as a

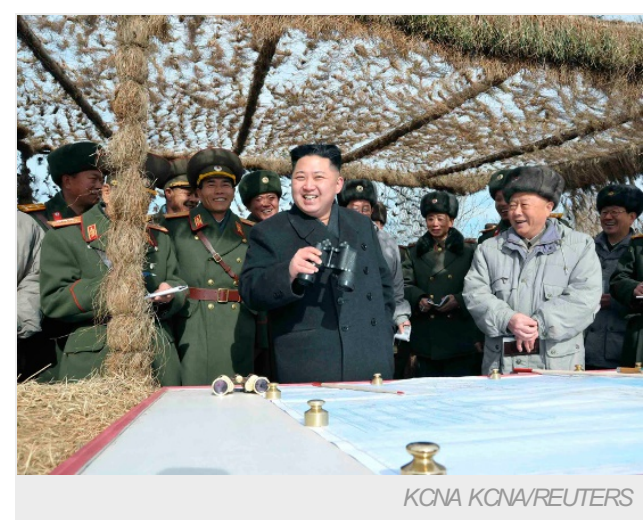

Despite the diplomatic breakthrough over North Korea's nuclear programme, supreme leader Kim Jong-un's cooperation with the West is far from assured. bargaining chip. In exchange for disabling its 5-megawatt reactor at Yongbyon in 2008, North Korea was removed from the United States' famous 'axis of evil' list (which included Iraq and Iran) and supplied with fuel aid.

The agreement is the first major international political deal made by the nation's new leader, Kim Jong-un, who came to power in December 2011 following the death of the previous incumbent, Kim Jong-il. But that doesn't necessarily mean that the new leader is seriously considering cooperation with the West, warns Duyeon Kim, Deputy Director of Nuclear Non-Proliferation at the Center for Arms Control and Non-Proliferation in Washington DC. Kim says that negotiations had been ongoing since before Kim Jong-il's death.

Both North Korea and the United States seem hopeful, yet wary. The state department warned of "profound concerns" regarding North Korea's behaviour generally, and the Korean Central News Agency warned that the moratorium would extend only "while productive dialogues continue".

Duyeon Kim notes that there is no timeline for either the moratorium or the resumption of inspections. "We will have to see whether North Korea follows through," she says.

Nature | doi:10.1038/nature.2012.10139 